\title{
Trends in the utilization of outpatient advanced imaging after the deficit reduction act.
}

\author{
David C Levin \\ Thomas Jefferson University \\ Vijay M Rao \\ Thomas Jefferson University \\ Laurence Parker \\ HealthHelp, Inc
}

\section{Follow this and additional works at: https://jdc.jefferson.edu/radiologyfp \\ Part of the Radiology Commons \\ Let us know how access to this document benefits you}

\section{Recommended Citation}

Levin, David C; Rao, Vijay M; and Parker, Laurence, "Trends in the utilization of outpatient advanced imaging after the deficit reduction act." (2012). Department of Radiology Faculty Papers. Paper 14.

https://jdc.jefferson.edu/radiologyfp/14

This Article is brought to you for free and open access by the Jefferson Digital Commons. The Jefferson Digital Commons is a service of Thomas Jefferson University's Center for Teaching and Learning (CTL). The Commons is a showcase for Jefferson books and journals, peer-reviewed scholarly publications, unique historical collections from the University archives, and teaching tools. The Jefferson Digital Commons allows researchers and interested readers anywhere in the world to learn about and keep up to date with Jefferson scholarship. This article has been accepted for inclusion in Department of Radiology Faculty Papers by an authorized administrator of the Jefferson Digital Commons. For more information, please contact: JeffersonDigitalCommons@jefferson.edu. 


\title{
As submitted to:
}

\section{Journal fo the American College of Radiology}

\author{
And later published as:
}

\section{Trends in the Utilization of Outpatient Advanced Imaging After the Deficit Reduction Act}

Volume 9, Issue 1, Pages 27-32, January 2012.

David C, Levin, Thomas Jefferson University

David.Levin@jeffersonhospital.org

\section{Vijay M. Rao, Thomas Jefferson University \\ Laurence Parker, HealthHelp, Inc.}

The Deficit Reduction Act (DRA) was passed late in 2005 and took effect at the beginning of 2007 [1-

4]. It had the effect of sharply reducing technical component payments for advanced imaging in private offices (including freestanding imaging centers). Prior to 2007, technical component payments for outpatient imaging were based on 2 different fee schedules. The Medicare Physician Fee Schedule (MPFS) applied to imaging done in offices, while the Hospital Outpatient Prospective Payment System (HOPPS) applied to imaging done in hospital outpatient facilities. For most types of MRI and CT examinations and some nuclear medicine examinations, the MPFS technical component payments to imaging offices had been considerably higher than those paid to hospitals under the HOPPS. The DRA 
reduced payments for all office imaging to the lower of the 2 schedules. This resulted in dramatic cuts in Medicare revenues to owners of advanced imaging equipment in private offices. It was estimated that the average reduction in technical component payments in offices was 35\% for MRI, 25\% for MR angiography, $9 \%$ for CT, 37\% for CT angiography, and 16\% for nuclear medicine [5]. By making these cuts, federal policymakers hoped to save money by reducing the fees and also by reducing the incentive for physicians to place advanced imaging equipment in their offices.

In 2008, the Government Accountability Office (GAO) issued its first report on the effect of the DRA on imaging costs [3,6]. It indicated that Medicare Part B spending for imaging had grown from $\$ 6.7$ billion in 2000 to $\$ 13.8$ billion in 2006. This had represented a compound annual growth rate (CAGR) of $12.9 \%$ per year. But in 2007 , the first year of the DRA, spending on imaging dropped to $\$ 12.1$ billion - a decline of $12.9 \%$ from the previous year. Payments for the 3 advanced imaging modalities (MRI, CT, and nuclear medicine) dropped $14.8 \%$ in 2007.

Not surprisingly, these steep cuts sparked dismay and anger within the radiology community. This was compounded by the fact that a number of commercial payers adopted similar cuts [7]. The ACR and the National Electrical Manufacturers Association (NEMA) and several other organizations jointly formed the Access to Medical Imaging Coalition (AMIC), which attempted to overturn the DRA [8], but to no avail. A number of web sites representing various organizations weighed in with commentary on the DRA, all of it expressing concerns about the effects of the Act [8-15]. The concerns were that private office imaging facilities would be forced to close, that advanced imaging exams might therefore have to be shifted to less convenient hospital outpatient departments, and that access for patients might be 
jeopardized. Three years of nationwide Medicare data (2007-2009) is now available since the DRA took effect, and we wished to use these data to see if the Act has produced those effects.

\section{Methods and Materials}

We used the Medicare Physician/Supplier Procedure Summary Master Files (PSPSMFs) for 2000 through 2009. These files cover all beneficiaries in the traditional Medicare fee-for-service program (34,938,000 in 2009) but not those in Medicare Advantage plans. For each code in the Current Procedural Terminology, Version 4 (CPT-4) manual, the files show procedure volume and other administrative data. We aggregated all the CPT-4 codes for CT and CT angiography, MRI and MR angiography, and nuclear medicine (including PET) and tracked outpatient volume changes in the 3 modalities over the study period. Outpatient exams were identified by selecting Medicare's location (or place-of-service) codes for private offices (which includes freestanding imaging centers) and hospital outpatient departments (HOPDs). Private office data included facilities that were owned by radiologists, nonradiologist physicians, and companies or individual entrepreneurs who operated them as independent diagnostic testing facilities (IDTFs). Volumes were determined by tabulating global and professional component claims. Technical component claims were excluded to avoid double counting. All noninvasive diagnostic imaging claims were included, but claims for guidance of invasive procedures and for 3D rendering were not. In nuclear medicine, non-imaging function tests were excluded. For each

of the 3 modalities, compound annual growth rates (CAGRs) were calculated from 2000 through 2006 (before the DRA took effect) and compared with the CAGRs from 2007 through 2009 (after the DRA took effect). Comparison was also made of the trends in private offices and HOPDs. 
The volumes reported here are complete population counts. Therefore, they do not require inferential statistics, which test the relationship of a sample to a population.

\section{Results}

Table 1 shows both private office and HOPD Medicare volumes for each of the 3 modalities in 2000, 2006, and 2009. CAGRs (yearly growth) are shown for 2000-2006 and 2007-2009. Figures 1-3 show the growth trends for, respectively, CT, MRI, and nuclear medicine (including PET).

As noted in Table 1, rapid outpatient growth occurred in all 3 modalities from 2000 through 2006, moreso in offices than in HOPDs. Yearly growth in all 3 modalities in both the office and HOPD settings was far higher before the DRA took effect (2000-2006) than after it (2007-2009). In the 20072009 post-DRA period, the table compares volume changes in offices and HOPDs and reveals the following: CT grew more rapidly in offices than in HOPDs (CAGR of $2.1 \%$ vs. $0.5 \%$ ). Nuclear medicine volumes declined in both locations, but the drop seen in offices $(-1.7 \%)$ was less than that seen in HOPDs (-2.5\%). MRI volumes declined slightly in offices (-1.1\%) and increased slightly (1.0\%) in HOPDs.

Figure 1 shows the CT trends in offices and HOPDs. The large majority of these exams are done in HOPDs. In both settings, there was steady and rapid growth in the early years of the last decade. Flattening of the growth trend in HOPDs was first noted in 2006, and volumes remained generally stable thereafter, although a slight upturn occurred in 2009. In offices, steady growth occurred through 2007 (the first year the DRA was in effect), then volumes remained stable during the last 2 years of the study. 
Figure 2 shows the trends in MRI. Unlike CT, more of these exams have been done in offices in recent years than in hospitals. Rapid growth occurred in both settings in the early years of the last decade, but a slight flattening in the trendlines first appeared in 2005 and became quite apparent by 2006. Between then and 2009, volume rose very slightly in HOPDs and declined very slightly in offices.

Nuclear medicine trends (including PET) are shown in Figure 3. In 2000, similar numbers of these exams were performed in offices and HOPDs but since then, growth in offices has been far more rapid. This primarily reflects the high usage of stress myocardial perfusion imaging by office-based cardiologists [16]. In offices, flattening of the rapid growth trend first became apparent in 2005. Office volume peaked in 2006, declined slightly in both 2007 and 2008, then declined more rapidly in 2009. In HOPDs, slow growth occurred from 2000 through 2004, followed by slow decline through 2009. Because PET is a relatively young technology that is of great interest, we have shown its growth in a separate graph in figure 4. The graph starts in 2002 because that is the first year in which PET was approved for reimbursement for some indications by Medicare. The overall volumes are much lower than those of the other modalities, but rapid growth can be seen in both the office and HOPD settings. Some of this is due to expansion of the indications for coverage in recent years. Growth occurred somewhat more rapidly in offices in the early years, but it began to slow somewhat in 2007 and by 2009 a definite slowdown was in evidence. At that point, the volumes in the 2 settings were approximately equal.

Total outpatient Medicare volumes (offices + HOPDs) for the 3 modalities in 2006 and 2009 were as follows: CT - 9,951,835 in 2006 vs. 10,265,955 in 2009 (+3.2\%); MRI - 5,084,802 in 2006 vs. 5,067,344 in 2009 (-0.3\%); nuclear medicine 9,434,073 in 2006 vs. 8,897,663 in $2009(-5.7 \%)$. 
The percent share of all advanced imaging done in offices was $51.7 \%$ in 2006 , compared with $51.3 \%$ in 2009.

\section{Discussion}

As noted earlier, the DRA cuts posed 3 related questions or concerns from a health policy perspective. Would private office imaging facilities be forced to close? Would advanced imaging exams therefore have to be shifted to less convenient HOPDs? Would patient access to advanced imaging exams be jeopardized?

There are no precise data available anywhere on how many imaging office facilities may have closed since the DRA took effect. Although some have undoubtedly closed, others may have opened. In areas where some offices have closed, other remaining offices may have had excess capacity and been able to absorb the exam volume that had been displaced by those closures. Among those that have closed, the reasons can be unclear and may have nothing to do with the DRA. For example, in our area, we are aware of IDTFs that were closed because of mergers of their corporate owners. Other office facilities closed because of adverse reimbursement policies instituted by commercial payers, in addition to the cuts imposed by Medicare. If large scale closures of imaging offices had resulted from the DRA, one would have expected to see substantial decreases in Medicare office volumes of advanced imaging from 2007-2009 and concomitant increases in HOPD volumes as exams shifted to the hospital facilities. The data in the Table and Figures 1-3 do not show either of these things happening. On the contrary, after the DRA took effect (2007-2009 data), CT actually grew more rapidly in offices than in HOPDs ( CAGR of $2.1 \%$ vs. $0.5 \%$ ). Nuclear medicine volumes decreased in both settings, but offices fared better 
in that their volume loss was proportionately less than that in HOPDs (CAGR of $-1.7 \%$ in offices vs. $2.5 \%$ in HOPDs). In MRI, there were small losses in offices (-1.1\%) and small gains in HOPDs $(+1.0 \%)$. The PET trend in offices (Figure 4) showed definite slowing of the rapid growth in 2009, but a small increase in volume still occurred.

In regard to access, there is no evidence that access to CT or MRI for Medicare beneficiaries was compromised to any great extent by the DRA. Compared with 2006, overall outpatient MRI volumes in 2009 were largely unchanged and outpatient CT volumes were higher. Nuclear medicine presents a somewhat more worrisome picture, however. HOPD nuclear medicine volumes began to decline in 2005 (Figure 3), well before the DRA. Office nuclear medicine, which is dominated by radionuclide myocardial perfusion imaging performed by cardiologists, began to show flattening in its growth in 2005, reached a peak in 2006, dropped slightly in 2007 and 2008, then dropped somewhat more rapidly in 2009. From 2006 to 2009, overall outpatient nuclear medicine volume dropped 5.7\%. Although there was no evidence of a shift from offices to HOPDs, this could signify loss of access to outpatient nuclear medicine for some seniors. To compound the problem, additional large cuts in reimbursements for radionuclide myocardial perfusion imaging were announced in late 2009 and scheduled to take effect in January 2010 [17].

It seems apparent from this and other studies [18] that a dramatic slowdown in growth of imaging began around the middle of the last decade, after years of rapid increases. . The slowdown was not due to the DRA, or at least not solely to the DRA. The proof of this is that the slowdown was felt equally in HOPDs, which should not have been affected by the DRA. Moreover, the slowdown first became noticeable in 2005, even before the DRA was passed. There are several possible explanations for this 
trend [18]. First, there has been extensive discussion in recent years within the health care industry about the need to reduce costs, and physicians may be getting more cost-conscious. Second, there has been concern expressed about radiation exposure [19-22] and ordering physicians may be responding to that. Third, both the American College of Radiology and the American College of Cardiology have developed appropriateness criteria for imaging [23-25], and physicians may be paying more attention to these criteria. Fourth, the recession could be implicated, although the slowdown predates the onset of the recession by several years. Fifth, the commercial payers have in some cases begun taking steps to limit the specialties that are eligible for reimbursement for advanced imaging [26], and this may have helped cut down on self-referral. Finally, radiology benefits management companies (RBMs) have instituted preauthorization programs within the commercially insured population in recent years. Preauthorization is now in widespread use and makes it somewhat more difficult and inconvenient for physicians to order advanced imaging studies. Although traditional fee-for-service Medicare has not yet employed preauthorization, it seems likely that the RBMs have influenced ordering physicians and induced them to think more carefully about what imaging tests they order (or whether they should order them at all). We believe that of the six factors discussed above, the RBMs are probably the principal one behind the growth slowdown reported herein.

A possible limitation of this study is that we evaluated overall utilization of advanced imaging, but did not compare the trends among radiologists and nonradiologist physicians. To make such a comparison would have entailed using a different methodology, which was not compatible with the aims of this study. Such a comparison has been made in the past [4] with data from 2007, the first year the DRA was in effect. 
There are several perspectives from which to view these data. From the perspective of health policy planners and federal government officials, the DRA appears to have achieved some of its goals. Payments for imaging were sharply reduced and it does not yet seem that access for seniors to CT and MRI has been compromised. Our perspective as radiologists is less sanguine, however. Nuclear medicine outpatient volume dropped 5.7\% from 2006 to 2009, despite rapid growth in PET. This could signify loss of access to this modality for Medicare beneficiaries and be a harbinger of things to come in CT and MRI if further reimbursement cuts are imposed by the Centers for Medicare and Medicaid Services (CMS). If that happens, more closures of private office imaging facilities can be expected, and that will lead to a diversion of advanced imaging to HOPDs. Although Medicare reimbursements for advanced imaging to HOPDs and private offices are comparable, commercial health insurers pay HOPD rates that are often far higher than rates they pay to offices (F. Kyle, personal communication, June 2011). If the commercial payers are forced to pay more for outpatient advanced imaging because these studies are shifted to HOPDs, the extra costs will get passed on to consumers in the form of higher premiums. Moreover, patient copays in HOPDs are higher than in offices. Officials at CMS have to consider ramifications such as these. If CMS payment policies result in large scale closure of office imaging facilities, it could have a substantial adverse impact on patients enrolled in the commercial health insurance market.

As radiologists, we can take some satisfaction in the remarkable flattening of the rapid growth in outpatient advanced imaging that our data demonstrate. This was a concern for health policy planners and now that growth has abated, there should be less downward pressure on imaging fees. Radiologists can also claim some credit for helping maintain access. In many instances, it is likely they were able to tighten their belts, institute new information technologies and work flows, and in general work harder 
and more efficiently. This may have allowed them to keep their office facilities in operation despite lower Medicare revenues.

In conclusion, we have examined recent trends in Medicare utilization of outpatient advanced imaging. There have been important developments. The rapid growth in outpatient CT and MRI that characterized the years prior to 2005 has largely abated. In nuclear medicine, there has actually been a substantial decline, despite rapid growth in PET. These changes do not appear to have been caused by the DRA, as there has not been a large shift of volume from offices to HOPDs. Although access for Medicare beneficiaries to outpatient CT and MRI does not yet appear to have been jeopardized, there is reason to be concerned about access to nuclear medicine, because of the nearly $6 \%$ drop in outpatient volume between 2006 and 2009. This could signify that the limits of resilience have been exceeded among some physicians in that discipline. Further cuts in Medicare reimbursements could bring about a similar situation in CT and MRI, and this could have adverse consequences not only for seniors but also for younger patients who are commercially insured. The complex interplay between physician fees and their willingness to provide services goes on and will have to be carefully watched in the coming years. 


\section{$\underline{\text { References }}$}

1. Moore AV Jr. Radiology and the health care reform debate. J Am Coll Radiol 2006;3:569-570.

2. Moser JW. The Deficit Reduction Act of 2005: Policy, politics, and impact on radiologists. J Am Coll Radiol 2006;3:744-750.

3. Levin DC, Rao VM, Parker L. Physician orders contribute to high-tech imaging slowdown. Health Affairs 2010;29:189-195.

4. Levin DC, Rao VM, Parker L, Frangos AJ. The disproportionate effects of the Deficit Reduction Act of 2005 on radiologists' private office MRI and CT practices compared with those of other physicians. J Am Coll Radiol 2009;6:620-625.

5. Patti JA. The economic environment of 2006: How safe is your practice and what you can do to protect it. J Am Coll Radiol 2007;4:97-1016.

6. U.S. Government Accountability Office, publication number GAO-08-1102R. Medicare: Trends in fees, utilization, and expenditures for imaging services before and after implementation of the Deficit Reduction Act of 2005. Available at: http://www.gao.gov/new.items/d081102R.pdf. Accessed December 1, 2009.

7. Moser JW, Hastreiter DM. 2007 survey of radiologists: Source of income and impact of the Deficit Reduction Act of 2005. J Am Coll Radiol 2009;6:408-416.

8. NEMA communications department. NEMA continues its push to delay Medicare imaging cuts. Available at: http://www.nema.org/media/pr/20061109a.cfm?renderForPrint=1. Accessed June 7, 2011. 9. Renard SR. The Deficit Reduction Act: What we can do about it. Diagnostic Imaging Scan, June 2006. Available at: http://radiology-services.com/pdf/DI_scan_column_pdf_June_06.pdf. Accessed June 7, 2011. 
10. American College of Radiology. Moran report: Nearly nine out of 10 imaging procedures affected by DRA cuts would be reimbursed below cost of providing the exam. Availabe at:

http://www.acr.org/secondarymainmenucategories/newspublications/featuredcategories/currentACRnew s/archive/moran_report091806.aspx?css=print. Accessed June 7, 2011.

11. Radiological Society of North America. Physicians seek relief in DRA's second year. Available at: http://www.rsna.org/publications/rsnanews/January-2008/physicians_feature.cfm. Accessed June 7, 2011.

12. Smith GG. Imaging reimbursement cuts may harm rural practices, patients. RSNA News, May 2006. Available at: http://www.rsna.org/publications/rsnanews/may06/cuts_may06.cfm. Accessed June 7, 2011.

13. Legislative watch: AMIC perseveres in battling imaging cuts. ImagingBiz.com, May 15, 2007. Available at: http://www.imagingbiz.com/articles/view/legislative-watch-amic-perseveres-in-battlingimaging-cuts. Accessed June 7, 2011.

14. Brune B. Sector prepares for the worst. Medical imaging businesses brace for cuts to Medicare. Houston Chronicle, July 18,2006. Available at:

http://www.chron.com/disp/story.mpl/business/4053594.html. Accessed June 7, 2011. 15. Michael S. Imaging volume dip could signal access problems, alliance says. Diag Imaging, February 9, 2011. Available at: http://www.diagnosticimaging.com/display/article/113619/1794712. Accessed June 7, 2011.

16. Levin DC, Rao VM, Parker L, Frangos AJ, Intenzo CM. Recent payment and utilization trends in radionuclide myocardial perfusion imaging: Comparison between self-referral and referral to radiologists. J Am Coll Radiol 2009;6:437-441. 
17. Sternberg S. Cardiologists sue Sebelius over Medicare fee cuts. USA Today, December 28, 2009. Available at: http://www.usatoday.com/news/health/2009-12-23-heart29_ST_N.htm. Accessed June $21,2011$.

18. Levin DC, Rao VM, Parker L, Frangos AJ, Sunshine JH. Bending the curve: The recent marked slowdown in growth of noninvasive diagnostic imaging. AJR 2011;196:W25-W29.

19. Brenner DJ, Hall EJ. Computed tomography: an increasing source of radiation exposure. N Engl J Med 2007;357:2277-2284.

20. Fazel R, Krumholz HM, Wang Y et al. Exposure to low-dose ionizing radiation from medical imaging procedures. N Engl J Med 2009;361:849-857.

21. Smith-Bindman R, Miglioretti DL, Larson EB. Rising use of diagnostic medical imaging in a large integrated health system. Health Aff (Millwood) 2008;27:1491-1502.

22. Einstein AJ. Radiation protection of patients undergoing cardiac computed tomographic angiography. JAMA 2009;301:545-547.

23. American College of Radiology. Appropriateness criteria. Available at www.acr.org/secondarymainmenucategories/quality_safety/app_criteria.aspx. Accessed August 23, 2011.

24. Hendel RC, Berman DS, Di Carli MF et al. ACCF/ASNC/ACR/AHA/ASE/SCCT/SCMR/SNM 2009 appropriate use criteria for cardiac radionuclide imaging. Circulation 2009;119:e561-e587.

25. Hendel RC, Patel MR, Kramer CM et al. ACCF/ACR/SCCT/SCMR/ASNC/NASCI/SCAI/SIR 2006 appropriateness criteria for cardiac computed tomography and cardiac magnetic resonance imaging. $\mathbf{J}$ Am Coll Cardiol 2006;48:1475-1497.

26. Levin DC, Rao VM, Kaye A. Turf wars in radiology: recent actions against self-referral by state governments, commercial payers, and Medicare - hope is on the horizon. 
